\title{
Pediatric Intervention or Procedure
}

National Cancer Institute

\section{Source}

National Cancer Institute. Pediatric Intervention or Procedure. NCI Thesaurus. Code C90341.

A diagnostic or therapeutic course of action usually performed on patients under the age of 18. 